www.jmscr.igmpublication.org

Impact Factor (SJIF): 6.379

Index Copernicus Value: 71.58

ISSN (e)-2347-176x ISSN (p) 2455-0450

crossref DOI: https://dx.doi.org/10.18535/jmscr/v6i5.122

Journal Of Medical Science And Clinical Research

\title{
A Cross Sectional Study to find out Awareness about use of Health Applications on smart phones among the General Population of Indore
} \author{
Authors

\section{Dr Deepa Raghunath ${ }^{1}$, Dr Akansha Kalra ${ }^{2}$, Dr Sanjay Dixit ${ }^{3}$, Dr Shagun Rampuria ${ }^{4}$,} \\ Dr Shefali Pawar ${ }^{5}$, Dr Shubham Thori ${ }^{6}$ \\ ${ }^{1}$ Associate Professor, ${ }^{2}$ PG Resident, ${ }^{3}$ Professor and Head, ${ }^{4,5,6}$ Student \\ Department of Community Medicine, MGM Medical College, Indore, MP, India \\ Corresponding Author \\ Dr Akansha Kalra \\ Mob: 7526061503, Email: dr.akanshakalra@gmail.com
}

\section{Abstract}

Background: The term mHealth (mobile health) is the use of mobile phones and communication devices to educate consumers about preventive health care services. Health is important because it makes healthcare practices accessible to the public through mobile communication technologies in a variety of ways.

Objectives

1. To find out the awareness and knowledge of people about the use of health applications in smart phones in the urban population of Indore.

2. To find out the duration and regularity of use of mHealth apps.

3. To find out the benefits of mHealth app among the people of Indore city.

Methodology: A community based cross sectional house to house survey was conducted among randomly selected 150 residents of Indore city. People above 15 years of age using Android and iOS phones and giving consent were included in the study. A pretested semi structured questionnaire was used. Data was entered in excel sheet and analysed using SPSS software.

Results: The most common age group of the participants was 17-26 years (68\%) in our study. It was found that $73 \%$ of the participants were aware about the health applications and most of them knew about applications related to weight loss (54.8\%) and availability of health facilities (43\%). Only 39\% participants were using heath applications out of which the most widely used were apps for finding nearby doctor (23\%), followed by apps for physical fitness and yoga (21\%). Among the ones using the health applications, 95\% thought that the use of health applications have benefitted them by providing better selfcare and health information. Although many participants thought that apps are beneficial, only few were using apps regularly and entering data on time and few were referring to a doctor or a dietician if they were guided by the app to do so. Although a large percentage of study population were aware of health applications, only a smaller group were using health apps. Most of the participants stopped using health applications due to lack of interest, too much of time consumption, confusing to use and cost factor.

\section{Introduction}

The term mHealth (mobile health) is the use of mobile phones and communication devices to educate consumers about preventive health care services. mHealth apps cover communication between users and healthcare systems (with call 
centers, and appointment and exact treatment reminders), monitoring and surveillance (with patient monitoring applications and surveys), and information access (with health records and medical diagnoses). mHealth is important because it makes healthcare practices accessible to the public through mobile communication technologies in a variety of ways (e.g., providing healthcare information, collecting health data, observing patients, etc.). mHealth can be used for disease self-management and remote monitoring of patients with long term conditions like diabetes, hypertension, depression etc. which provides long-term care, improves self-efficacy, and minimizes healthcare costs. A study conducted in Australia found that people used health applications for self-monitoring of long term diseases like blood pressure, asthma, diabetes etc $^{[1]}$.It has also been thought to be an important contributor to behavior Change intervention and disease management. A study done in the Midwest region of US in which they found that the barrier to the adoption of health application is low awareness, lack of need and lack of app literacy and if people used apps previously and they stopped using it because of lack of time ${ }^{[2]}$. The Ministry of Health and Family Welfare, Government of India has set up the National Health Portal to provide healthcare related information to the citizens of India and to serve as a single point of access for consolidated health information. There are multiple applications that can be accessed through this portal and covers common medical problems that are prevalent in community, are on the rise and for which people need awareness. It includes various health's apps like mDiabetes, no more tension, NHP Mission Indradhanush, mCessation Programme (Quit Tobacco for Life), NHP Health Directory Services, Mera Aspatal, Swasthya Bharat Mobile Application, Fights Dengue, Pradhan Mantri Surakshit Matritva Abhiyan and many other ${ }^{[3]}$. mHealth aims to improve care by making health information easily accessible for patients with long-term conditions such as diabetes, hypertension. The focus on mHealth is rapidly growing, due to the rise in production of smart phones and tablets that enable easier access to the Internet making them an integral part of the healthcare landscape mHealth applications include the use of mobile devices in collecting community and clinical health data, delivery of healthcare information to practitioners, researchers, and patients. There are more than 100,000 mobile applications today ${ }^{[4]}$. Mobile apps are now commonly incorporated in the design of health promotion programs ${ }^{[5]}$. Hence this study tries to find out the awareness and knowledge of people about the use of health applications in smart phones in the urban population of Indore, the duration and regularity of use of mHealth apps and to find out the benefits of mHealth app among the people of Indore city.

\section{Methodology}

A community based cross sectional house to house survey was conducted among randomly selected 150 residents of Indore city. People above 15 years of age using Android and iOS phones and giving consent were included in the study. A Pretested semi structured questionnaire was administered which included demographic characteristics like age, gender, education\& occupation, awareness and knowledge of people regarding health applications, duration, frequency and regularity of use, most common apps used by the people, benefits of health applications, reason of using health applications and reason for stopping their use. Data was entered in SPSS software and analysis done wherever necessary. Basic descriptive statistics was used including means, standard deviations for continuous data and proportions for categorical data. Chi square test was applied wherever necessary. The study was conducted for duration of 3 months (November 2017- January 2018). Assuming prevalence to be $50 \%$ and margin of error to be 10 , sample size was calculated to be $100\left(4 \mathrm{pq} / \mathrm{n}^{2}\right)$. Sequential sampling was used. The first 150 
people fulfilling the inclusion criteria and giving consent for the study were taken for the study.

\section{Result}

The most common age group of the participants was 17-26 years (68\%) in our study. Mean age of the sample was 25.57 and standard deviation was 6.514. Out of total study population $57 \%$ of the subjects were males and $43 \%$ were females. Further participant's demographic profile is shown in Table 1

Table 1: Sample Demographics

\begin{tabular}{|l|c|c|}
\hline Characteristics & Frequency & Percentage \\
\hline Age & & \\
\hline 17-26 year & 102 & $68 \%$ \\
\hline 27-36 year & 38 & $25.33 \%$ \\
\hline 47-46 year & 08 & $5.33 \%$ \\
\hline 57-56 year & 01 & $0.67 \%$ \\
\hline Gender & 01 & $0.67 \%$ \\
\hline Female & 64 & $42.67 \%$ \\
\hline Male & 86 & $57.33 \%$ \\
\hline Education & 23 & $15.33 \%$ \\
\hline Post Graduate & 95 & $63.33 \%$ \\
\hline Graduate & 30 & $20 \%$ \\
\hline $\begin{array}{l}\text { Intermediate or Post High } \\
\text { School }\end{array}$ & 02 & $1.33 \%$ \\
\hline High School Certificate & 83 & $55.33 \%$ \\
\hline Occupation & 67 & $44.66 \%$ \\
\hline $\begin{array}{l}\text { Unemployed mainly consisting } \\
\text { of students. }\end{array}$ & & \\
\hline Employed & & \\
\hline
\end{tabular}

In our study we found that $73 \%$ of the participants were aware about the health applications. There was no significant difference found between the awareness of health apps between male and females. (Pearson Chi square test value 0.679 andp value 0.410). Mainly study population consisted of graduates followed by intermediate students. There was no statistically significant association between mHealth awareness and education of study population. (Pearson chi square test value 3.712 and $p$ value 0.294 ). Table 2 shows the knowledge of, participants about health applications. It was found that most of them knew about applications related to weight loss (54.8\%) and applications that provided information regarding health facilities (43\%) while few had knowledge about applications related to a particular disease (20.5\%) and only $9.6 \%$ knew about Government provided applications.

Table 2: Knowledge about different applications

\begin{tabular}{|l|c|c|}
\hline APPLICATIONS & FREQUENCY & PERCENTAGE \\
\hline Related to weight loss & 80 & 54.8 \\
\hline $\begin{array}{l}\text { Related to a particular } \\
\text { disease }\end{array}$ & 30 & 20.5 \\
\hline $\begin{array}{l}\text { Government provided } \\
\text { applications }\end{array}$ & 14 & 9.6 \\
\hline $\begin{array}{l}\text { Applications about } \\
\text { health facilities }\end{array}$ & 63 & 43.2 \\
\hline None & 39 & 9.6 \\
\hline Others & 5 & 1 \\
\hline
\end{tabular}

*participants opted for more than one option, hence the total percentage is more than 1000nly $39 \%$ participant's used health applications out of which the most widely used were apps for finding nearby doctor (23\%), followed by apps for physical fitness and yoga (21\%), pedometer (20\%) and hospital finder (20\%). Among the participants using health applications, $27 \%$ of them had started using health applications 3-6 months back, while $22.8 \%$ of the study population has been using it for more than a year. Out of the total participants using health applications, $81 \%$ of them spent $5-10$ minutes daily using the application. Only $34.56 \%$ used app regularly and entered their data on time. According to $34 \%$ participants, the reason for using health app was to achieve their goal on time, $26 \%$ were using it because their friends recommended them, and $21 \%$ mentioned that they wanted to try something new while $16.5 \%$ found that apps keep their records on time.49\% of the sample thought that use of application is beneficial to them (irrespective of their use). $65.54 \%$ of the study populations were not willing to pay for the applications, but about $31 \%$ of them were willing to spend over health applications. Among the ones using the health applications, 95\% thought that the use of health applications have benefitted them, out of which, 29\% thought that mHealth apps provide better self-care, 28\% felt that health apps were a good source of health information, $22 \%$ felt that it has contributed to health improvement, and according to $15 \%$ 
participants health apps helped in better selfhealth record keeping. $67 \%$ of participants opined that their knowledge about disease and health has increased after using health apps, 22\% were not sure about the benefits and $11 \%$ felt that there was no change in their levels of knowledge. Among the participants using health applications, only $34 \%$ referred to a doctor or a dietician for follow up after the usage of health app. Out of the participants not using health applications, 40\% thought that they do not require them, 37\% are not aware of them, $18 \%$ thought that health apps were not helpful, $12 \%$ found the apps to be boring and 9\% told that they had used them earlier butit did not help them.

\section{Discussion}

This study showed that maximum applications familiar to the people are related to applications providing facilities like nearby doctor, apps for physical fitness like yoga, exercise, weight loss, pedometer, calorie counter and few of them knew about the other applications. This is consistent with another study done in Czech Republic where sport and exercise apps were used most frequently, followed by apps for healthy eating and apps targeting weight loss and health. ${ }^{[5]}$ This was in contrast to the findings of a prior study conducted in the metropolitan area of Perth, Australia, where people used health applications for self-care and monitoring of particular long term diseases like diabetes, celiac disease, pain management, depression, asthma, chronic migraine, menstrual irregularities ${ }^{[1]}$. It was found that most people used application weekly for few minutes and they used the app prior to meeting initial milestones which significantly decreased thereafter. In our study also, maximum people desired to continue the use of applications till their goal is met with. The people not using health applications do not find the need to use them. Also some people have stopped their use due to lack of interest, time and app illiteracy. These findings were in concordance with the findings of a study done in the Midwest region of US in which they found that the barrier to the adoption of health application is low awareness, lack of need and lack of app literacy and if people used apps previously and they stopped using it because of lack of time. Although a large percentage of study population were aware of health applications, only a smaller group were using health apps which means that although people had knowledge about health apps, only few were practicing it. $27 \%$ of the sample started using health apps 3-6 months back which means that people are not very enthusiastic in making use of various health apps. Most widely used apps were nearby doctor, fitness and yoga, pedometer which means that still people are unaware of many other health apps. Although many participants thought that apps are beneficial only few were using apps regularly and entering data on time and few were referring to a doctor or a dietician if they guided by the app to do so. Many participants were not using mHealth apps as they thought they don't require them and don't know about them while according to some the health apps are boring and their usage will not help them. Most of the participants stopped using health applications due to lack of interest, too much of time consumption, were finding it confusing to use and cost factor.

\section{Conclusion \& Recommendations}

Although many participants were aware of the health apps and thought them to be beneficial but there was lack of motivation with regards to its usage therefore mHealth apps should be promoted on regular basis through mass media. They did not know about various other mobile health apps. Use of self-care and self-monitoring apps was low so these apps should be vigorously promoted. Besides this, provision of inbuilt applications smart phones may also help. The app should be made simple, attractive, and easy to operate. For future generations to utilize the benefits of health apps, mHealth app information should also be included in health education campaigns. For sustained use of mHealth apps they should be made more interesting, less time and cost 
consuming. There were some limitations in our study. The results were entirely based on answers given to the questionnaire, so there is possibility that some questions may be misinterpreted or intentionally wrongly answered. Not all mHealth apps have been discussed in our study as participants told only about the apps they were using. As most of our study population consisted of young age group therefore awareness of health apps among old population could not be answered.

\section{References}

1. Kevin Anderson, Oksana Burford, Lynne Emmerton (2016) Mobile Health Apps to Facilitate Self-Care:A Qualitative Study of User

Experiencesjournals.plos.org/plosone/artic le?id=10.1371/journal.pone.0156164

2. W Peng (2016)A qualitative study of user perceptions of mobile health apps | BMC ...https://bmcpublichealth.

biomedcentral.com/articles/10.1186/s 1288 9-016-3808-0

3. National Health Portal of India, Gateway to Authentic Health Information https://nhp.gov.in/Ministry of Health and Family Welfare, Govt of India.

4. R Kayyali ( 2017)Awareness and Use of mHealth Apps: A Study from ... - NCBI NIHhttps://www.ncbi.nlm.nih.gov/pmc/art icles/PMC5597158/

5. S Elavsky, David Smahel, Hana Machackova (2017) Who are mobile app users from healthy lifestyle websites? Analysis of patterns of app use and user characteristics

https://www.ncbi.nlm.nih.gov/pmc/articles /PMC5684086/ 